all these cases was in some measure different, though their issue was one. In the first case, a mild mercurial course and counterirritation were practised. In the second no depletive measures were adopted, but, on the contrary, a stimulant and a strengthening course was followed, whilst, in the third case active depletion and a free use of mercury internally and externally, met with no better result than the two other modes of treatment. No hint can thus be drawn regarding the treatment of tubercular meningitis from these cases.

The treatment I should be most inclined to rely upon would be counterirritation without active depletion; for blistering at the nape of the neck, and behind the ears is so often seen to be followed by marked benefit in cases of continued headache, though in these it is, of course, impossible to prove that meningitis has been averted.

The last point $I$ would notice in these interesting cases, is a pathological one, viz., the relation between the post mortem appearances at the base of the brain and the manifestations of cerebral disease during life. In the first case, the membranes at the base of the brain were affected, and the right third nerve most notably so, manifested before death by the most complete paralysis of its orbital branches to the superior, inferior, and internal recti muscles, to the iris, and to the levator palpebræ superioris.

In the second, the inflammation was more extended over the base of the brain, involving the nerves only in a general way and accordingly we find, during life, besides the coma, only slight divergent squint with affection of the pupils.

Ir the third case the inflammation was seated much further back than in the first two, with which we find the symptoms were in accordance, for the muscles of the eyes and the irides were very slightly affected, shewing that the third nerves, which arise anteriorly, were little involved, whilst the pheno mena noticed in this case and absent in others, viz., hiccough, slow pulse, and irregular respiration, may be traced to the fact of the inflammatory affection being seated principally around the medulla oblongata and in the fourth ventricle, as the par vagum, which supplies the diaphragm and furnishes branches to the cardiac and pulmonary plexuses, takes its deep origin from nuclei of grey matter in the medulla oblongata at the floor of the fourth ventricle, and hence would be exposed directly to the effect of the inflammatory process.

That these conclusions are correct is corroborated by the experiments of E. H. Weber, which tend to prove that stimul conveyed through the pneumogastric nerves retard the heart's action, and also by the experiments which have been repeatedly made in dividing these nerves, after which the respiration im mediately becomes slower.

\section{CASES OF DIPHTHERIA.}

By Nathanier Crisp, Esq., Swallowfield, Berks. I [Read beforc the Reading Pathological Soeiety, June 1860.]

Mr. President and Gentlemen,-Several cases of diphtheria having recently been under my care, I venture very briefly to bring them under your notice, and in so doing shall endeavour somewhat to classify them, and then make some short remarks.

The first two cases occurred in one family during June 1859 , in the persons of two brothers,-one aged 13, the other 5 years. The elder brother was attacked first; the tonsils and uvula were thickly covered with a well marked tenacious membrane, which could be peeled off in large flakes; prostration was extreme, accompanied by much difficulty in breathing; expectoration was very profuse, consisting of thin mucus, mixed with many shreds of membrane; slow convalescence took place, retarded after careless exposure and over exertion, by an attack of scvere general anasurca; ultimately he recovered well. The younger brother was shortly afterwards attacked with the same class of symptoms; the disease, in this case, also involved the nares; he soon recovered, but for some time suffered from fluids passing into the nares during deglutition.

The next two cases also occurred in one family, but at different times; the first in a child 3 years old, during September, 1859. The disease had existed for some days before I saw him, and at that time he was moribund, or almost so, death taking place early the next day. The great difficulty experienced in getting a view of the throat, the very laryngeal breathing, and the rapid death, made me, at the time, inclined to regard it as a case of croup; but my opinion was altered when, about four months after his death, a brother, aged 12, was attacked in a similar manner; his tonsils presented well marked patches of membrane; but from the first the attack was milder, and he recovered.

The next series of cases occurred in one family and presented many points of peculiar interest. In October 1859, a daughter, aged 20, who had been helping look after a bedridden old man, residing in a cottage opening into a stagnan reeking farm-yard, came home to her parents' cottage, situated about a mile from her former abode, with sore throat. When seen by me, it appeared likely to prove a severe case of diphtheria, the symptoms and appearances being well marked but she soon recovered. Six months afterwards, or at the end of last April, a sister, 6 years old, began to ail, apparently without any specific cause, and rapidly got worse; the leathery membrane was thickly laid over the throat as far as could be seen; the breathing became more and more laryngeal; exhaustion, great from the first, was soon extreme, and she died on May 3rd, the fourth day after she was seen. On May 7 th, a brother nine years old, began to complain in the same way; the right tonsil presented a well marked patch of leathery membrane, its upper edge peeling off and hanging down exhibiting well its tough consistence; the throat became more and more involved for some days, and then very gradually began to recover its normal state; and he is now, after a prolonged period of extreme weakness, tolerably well. On May 11th, another sister, aged 14, was attacked; this case, from the first well marked, for a day or two appeared yielding to treatment; but as the larynx became involved, very profuse expectoration took place of thin mucus mixed with numerous tlakes of tenacious membrane, some of which exhibited in a marked manner the shape of the interior of the larnyx and trachea, one large piece, in particular, plainly having been detached from the lower end of the trachea and the adjoining portion of one of the bronchi; the strength rapidly gave way, and death ensued on the tenth day of the illness. The mother now complained of sore throat; but beyond a somewhat relaxed condition, nothing marked appeared, and she showed no more signs of diphtheria. On June lst, another daughter, aged 11, was seen with many symptoms of diphtheria; she only presented a swollen condition of one tonsil, but much more general disturbance of the system than usually accompanies such a state of throat, and she, as well as her mother, recovered after a few days. On June 2nd, a brother, aged 13, after complaining for one day, presented well marked deposit on the left tonsil and appeared likely to have a severe attack, but slowly recovered.

About two months prior to the occurrence of these cases, in the same parish, but at some distance apart, five cases occurred in one family ; four children, aged respectively $3,6,8$, and 10 years, being ill at the same time, and shortly after the mother sickened. All these cases were well marked, and severe in two instances, but all did well. Erythems nodosum of a severe type retarded the convalescence of the eldest child.

In a cottage at the back of the one where the first two cases occurred in June 1859 , a strong robust young man, 21 years of age, died in December last. I attended him only during tho last part of his illness; his prostration was most extreme ; expectoration was very large in quantity, consisting of offensive thin mucus, a little streaked with blood and mixed with shreds of diphtheritic membrane; he rallied somewhat, and appeared progressing favourably; but died suddenly, apparently suffocated.

In February last a delicate lad, aged 7, living about a hundred yards from this last case, began to complain of sore throat, the right tonsil was first attacked, and then the left; it threatened to assume a severe form, but the child did well, notwithstanding a relapse and recurrence of the deposit in the throat.

The next series of cases originated, and with two exceptions were attended, in the parish of Bramshill, on the edge of a large and somewhat marshy common. In February 1860, a lad, aged 16, came home from a farm.house situated on this common, where he had been for some time previously living, to a village, two or three miles off; he was then complaining of sore throat, and when I saw him, a day or two afterwards, decided symptoms of diphtheria existed, prostration rapidly supervened, accompanied by delirium and very abundant expectoration of the same nature as before mentioned; he died somewhat suddenly the sixth day of his illness. The next week his father was laid up; the attack was mild, and he did well, but he is still somewhat weak, and complains of tingling and numbness of his hands. A month after this, a case occurred in a cottage, a short distance from the farm-bouse just referred to. The patient, in this case, was a boy, 9 years old; the symptoms 
were very severe; expectoration was extraordinarily copious, and of the same nature as in the other cases; suppuration took place in the cervical glands; and he died about the tweifth day. Two days before his death, a girl, 9 years old, residing at the other end of the common, was seized with similar symptoms; the disease ran a severe and rapid course, and she died on the fifth day. Sixteen days after this child's death, another girl, 9 years old, her constant associate and playmate, and residing in the adjoining cottage, was attacked; she has recovered, but after a severe struggle. Three days later, another girl, fourteen years of age, residing in a farm-house a short way off, and who frequently came to see the last two during their illness, and after the funeral of the first one remained in the same cottage, began to complain in a similar way, and died on the fifth day. Five days after this, the mother of this one was the subject of diphtheria; and at the same time an uncle also, who resided about half-a-mile off, and had sat up one night with his dying niece; the mother recovered, but still remains weak; the uncle made a rapid recovery. Almost immediately after this, a child of this man's, 3 years old, complained of sore throat, but there appeared nothing marked in this case, and the child was soon well. No more cases have appeared in this immediate neighbourhood; but a short way off, and in a locality very similar, a case occurred just afterwards; the boy was 6 years old, was very ill at first, but was soon convalescent. About the middle of last month attended a woman about 30 years of age, living far away from any of the above mentioned, in whom the disease had existed for some days; when first seen, the state of the throat was not clearly indicative of diphtheria; but the next day I was shown a distinct patch of membrane, evidently diphtheritic, which she had expectorated. Convalescence, in this case, was slow.

This completes the list of cases which have fallen under my notice in this neighbourhood-a total of 27 , not reckoning the two or three referred to, which were of too slight a nature to render one certain as to their true character; out of these 27 cases, 8 were fatal. The general symptoms and course of the disease were very similar in the different parties affected.

After a day or two of general malaise, sore throat would be complained of ; and if an examination were then made, one two, three, or four light ash-coloured spots, on a swollen and vascular tonsil or uvula, would be seen. These patches of deposit, in most cases primarily placed in the follicles, increased in size, and coalesced, forming a patch varying from the size of a sixpence to a sufficient magnitude to cover both tonsils and the uvula ; running forwards over the palate and dipping downwards as far as the eye could reach; in its earlier stage of a somewhat cheesy consistence, gradually increasing in tenacity, until a tough light-coloured membrane resulted, presenting much the appearance of the smoother portions of boiled thin tripe. In all the cases, more or less, difficulty in swallowing existed, often extreme; a symptom which in many cases on record has been wanting. The tongue was generally covered with a yellowish thick fur; a peculiar foetor often existed, the skin was usually of a somewhat leaden hue; and, in the severer cases, an extremely and strangely anxious look existed. Slight febrile disturbance was present at first; the pulse, in almost all, being quick, feeble, and often thready. In cases which terminated in recovery, the edges of the deposit, no longer spreading, became more defined, in some very markedly so; the tonsils and uvula presented vivid redness; and, in one or two instances, the ap pearance reminded me much of that assumed in the line of demarcation in gangrenous conditions; as the deposit decreased the power of swallowing returned, and with it strength was slowly regained.

Convalescence was, in one case, after early and imprudent exercise, retarded by severe general anasarca. A sharp attack of erythema nodosum occurred during the recovery of another; considerable hæmorrhage from the throat or nares took place in another; slight paralysis of the velum palati was observed in one or two of the cases; numbness of the hands continues to exist in one man, although he has otherwise recovered a prolonged and severe state of nervous depression still retains its hold of one woman, perhaps to be attributed as much to the shock she sustained, in the loss of her only child, as to any peculiar effect of the disease itself.

In the cases which terminated fatally, the disease travelled downwards; the larynx becoming more or less involved, in six out of the eight, in the most marked manner; the general distress was extreme, prostration rapid and great, the countenance becoming dusky and the breathing markedly diaphragmatic ; but death was apparently the result of exhaustion more than of actual asphyxia. In the instances in which the larynx was so implicated, expectoration was extremely copious and quite unlike that accompanying any other disease; one, two, or three pints a day in quantity; it consisted of offensive, thin, dirty, brown-coloured fluid, mixed with tenacions shreddy matter, and lumps of a cheesy and fatty-looking nature; streaks of blood were occasionally mixed with these products; in one or two of the cases, well marked casts of the interior of the trachea were observed. In one subject examined after death, the membrane clearly extended far into the bronchi, and in another nearly as far; the lungs, in these cases, being engorged with similar fluid to that expectorated during life. In two instances, one of which terminuted quite, and the other almost suddenly, the fatal issue must, I think, be attributed to a sudden accumulation of this secretion in the air-passages.

Eight fatal cases out of twenty-seven may appear a very large mortality; but it is not more than has occurred in some other places. Of seventy-four cases noticed in the BritisH MEDICAL Journat, twenty-six died; and a large number of these had all the advantages of hospital treatment, where, of course, much more can be done than in the cottages of the poor. Here we have often to contend against poverty and dirt; the obstinacy of ill-educated children, who, by their struggles, as much resist one's efforts to see or apply remedies to their throats, as their relatives do through having no moral control over them or by allowing false kindness to stand in the way of the steady pursuance of measures, because productive of some pain and discomfort. No one who has not experienced it can tell how vexatious and depressing to our energies it is to be called from one's bed, and to find, after a toilsome lonely ride, that no remedies have been applied; no medicines administered; no nourishment given for hours together; a disease markedly exhaustive in its tendency allowed full sway; all the instructions and orders we had given twelve hours before totally disregarded; and when the unfortunate doctor proceeds to enforce what ought to be done by the patient's own friends, he is looked upon as a brute, and every effort is employed, short of actual violence, to prevent his doing what he thinks right. This is no over-drawn picture in many cases: and, in addition to all these drawbacks, the unfortunate sufferer has to contend with the vitiated atmosphere of badly ventilated, ill lighted, overcrowded apartments; his friends make up their minds that the disease is almost necessarily fatal, and impress this upon his mind, if not in actual words, quite plainly by their actions and looks; when to all this is added, in some cases, the hardened indiffererce of relatives, no wonder that mortality is great. Against this high rate, it may be said that some have been more fortunate in their treatment; and I remember having seen a statement that one medical man had four hundred cases of diphtheria, one only fatal ; another, about the same number, with no fatal case : this is rather too much for my belief, and is making this disease one of the most amenable to treatment.

I omitted to state that in no cases could I find any connexion between the disease and scarlet fever. The urine was not tested in all cases; but, in those in which it was, albumen did not by any means constantly exist.

The treatment adopted was generally the same: the free application of a strong solution of nitrate of silver; alum and acid gargles; chlorate of potash and muriatic acid internally, quickly followed by quinine and sesquichloride of iron ; stimulants freely from the first. In two or three cases, in which the larynx was involved, emetics afforded relief, but only of a temporary nature; and the external application of iodine also was of some transient benefit. One general plan of treatment was pursued, as I considered that it was better to give a fair trial to one than to follow many; and, although in cases in which the windpipe was implicated, but little benefit resulted, the remedies mentioned certainly appeared to me to have marked effect when applied in time. Should any more severe cases come under my notice, I should be disposed to give chlorine a trial in some form, as a gargle or by inhalation.

Many such predisposing or exciting causes as we believe to be productive of or favourable to zymotic diseases in gerreral, existed in most of these cases. The first fatal case occurred in a small overcrowded cottage, extremelyill ventilated, so situated that hardly a ray of sun could enter, and which, without any particular bad drainage or such like, was the very spot one would select for disease to be rife. Another death took place in a cottage, not so badly ventilated, but having immediately beneath the bed-room window a stagnant open cesspool, receiving all decomposing household matters. Its contents were in contact with the cottage walls; and although a water-closet was placed a short distance off, I doubt not but that this slough was the re- 
cipient of much that ought to have been conveyed elsewhere. With its stench filling one's nostrils, the father could not allow that it was productive of harm, as it had been there for years. I had it filled up, but I see that it has been again opened, and is now in full use. At the back of the rank of cottages, where two children died, another such cesspool exists in close proximity to the well, and doubtless soaking into it, as the inhabitants tell me that the water soon becomes offensive, and that all such animals as frequently exist in wells soon die. By the side of another cottage, where five cases occurred, was a kind of shed; and in this shed, situated directly beneath the bedroom window, was a water-closet with an open cesspool and no drain to carry off the refuse matters from a family of eight or ten persons the stench on one hot day defies description. The diphtheritic children in another family were allowed to make use of the open ground immediately by the back door, as it was thought dangerous for them to go a few yards further to the water-closet. At the back of another cottage, a ditch, closed at one end, has become a stinking cesspool; whilst the last case existed in a cottage surrounded by many trees, almost inaccessible to light or fresh air, badly drained; and at its back the stable-yard exists on higher ground, and in its immediate vicinity, if not actually adjoining, were crowded poultry-houses; this patient had means at command, and could get all she required, or the case might have terminated less favourably.

P.S.-I had hoped that no other instances of this affection would have come under my notice, but shortly after writing the above $I$ attended a man living in quite a different locality to any of the preceding ones; he suffered in a marked but mild degree, and did well. He thought his illness might have arisen from drinking out of the same cup as a fellow-lubourer who was suffering from some affection of the mouth and throat. What this was, I could not ascertain. Two cases have also occurred in another district, marshy in its nature. One was a girl, aged 7 who had a severe attack about six weeks ago, but recovered favourably. Three weeks afterwards, a brother, 4 years old, was attacked; the throat, which was severely implicated, appeared to have recovered its healthy condition, but no strength was regained, and he died in the third week from sheer exhaustion. Throughout the whole time he was ill, extreme difficulty was experienced in making him submit to treatment, or take any nourishment. To this, more than to the disease itself, I attribute his decease. The mother of these two children had had some communication with one of the cases before mentioned; but the children none. At the same time as this last child was attacked, another child, 10 years old, living some five miles off, but near where other cases had occurred, was the subject of diphtheria of a very severe form; she also recovered as far as the throat was concerned, and appeared quite con. valescent, but very weak. In consequence of her mother being confined, for nearly a week she was much neglected, no proper nourishment being given her. Vomiting set in, and she died in thirty-six hours, the third week of her illness. On a post mortem examination, I discovered nothing to account for death, beyond a condition of the intestinal canal, plainly indicative of want of sufficient nourishment. On the same day on which I first saw this last case, I was called to a young woman who had come a day or two before on a visit to her friends, who resided a short way from one of the cases previously alluded to ; this proved a very severe case; the larynx became involved, expectoration was profuse, and of the nature already described, the urine was highly albuminous, and prostration was great. She, however, readily submitted to treatment, and persevered in taking everytbing that was ordered, and is now convalescent.

The treatment of this last set of cases, has been somewhat different from that pursued in the others; no caustic was applied to the throat. The three children used a gargle of sesquichloride of iron; and, when they could be prevailed upon, drank freely of the same. Inhalations of chlorine were also used. In addition to such remedies, the case last mentioned took for some time chlorate of potash with free chlorine.

In these, as well as in all the other cases referred to, as far as was practicable, I removed the false membrane day by day.

'That this disease is to a certain extent infectious is, I think, proved by the cases narrated, more especially by those occurring in Bramshill. Children are more prone to it than infants or adults, and are more likely to succumb to it than the latter mainly, I think, from not having sufficient self-control to allow of remedial measures being used.

Some of the cases referred to prove how eminently exhaustive it is in its nature, and that apparent convalescence is not a sure forerunner of recovery. Of one thing I am convinced; to a considerable extent it is amenable to treatment, and still more to be prevented by hygienic measures.

\section{Cransactions of 掘randbes.}

\section{CAMBRIDGE AND HUNTINGDON BRANCH.}

ON THE TREATMENT OF WOUNDS AND PATIENTS AFTER OPERATIONS.

By G. M. Humpeny, MI.D., F.R.S.

[Remarks made at the Meeting of the Cambridge Branch of the Association.] THE treatment of wounds and patients after operations is a matter of so much importance, that I need no apology for bringing it under your notice. The following brief remarks being based upon the practice followed in Addenbrooke's Hospital, it is right to state that the patients are chiefly agricultural labourers, and, on the whole, favourable subjects for operations.

Tying the Blood-Vessels. We take a great deal of pains in securing the blood-vessels. We tie a greater number of small vessels than is, I think, usually done. The surface of the wound is rubbed rather smartly with the sponge, to clear away the clots and excite the vessels to bleed; for even considerable arteries, such as the radial, ulnar, and facial, may contract, or be covered by coagula, so as to escape notice, unless this be done; and then they bleed after the wound has been closed. The vessels generally bleed most freely at the time of the operation, and are likely to give most trouble afterwards, if they be not well secured, in thin irritable persons, in whom the pulse is quick and sharp, and when there has been much disease in the part operated upon. I performed amputation in the thigh in two young men on the same day. One of them was delicate, emaciated, with long standing and extensive dis ease in the knee; the vessels bled vigorously, more than twenty were tied; and there was secondary hæmorrhage, which recurred and recurred again, and, in spite of all our efforts ultimately, proved fatal. The other patient was stout and healthy; the limb had been smashed by a thrashing-machine the femoral artery alone required a ligature; and there was no subsequent bleeding.

Care should be taken to tie the great vessels tightly. This may seem a needless remark; but I lost one patient, as I had reason to believe, in consequence of the fernoral artery not being tied sufficiently tightly. In another case, just before th wound was closed, I observed a slight leakage from the tied end of the femoral artery. Had not this been discovered, and the vessel been properly secured, hæmorrhage would, in all probability, have ensued. In a third case, I discovered, on sponging the wound carefully, a small orifice in the femoral artery, just above the ligature. In a case in which hæmorrhage proved fatal after amputation, I found, on dissection, wound in the posterior tibial artery above the ligature. This had been made by the point of the knife in cutting the posterior flap, and had escaped observation when the ligature was applied. Hæmorrhage after operations is, I suspect, in most cases, attributable to the fact that the vessels have not been properly secured. When it takes place, at whatever period it be after the operation, my own experience coincides with that of most authorities upon the subject, that it is, as a general rule, the best plan to open the wound, search for, and endeavour to tie, the bleeding vessel.

We need not be afraid of using many ligatures, for they do very little mischief. They excite scarcely any irritation; they are collected in one or two bundles; and, by affording a drain from the depths of the wound, they do rather good than harm, and facilitate, rather than impede, the healing processes. It is not worth while to annoy the patient by pulling at the liga tures, during the subsequent progress of the case, for the pur pose of ascertaining whether they be loose ; it is better to leave them to be discharged from the wound, or gently to draw them away when they are quite separated. I have not ventured upon a trial of the newly proposed plan of compressing the vessels by needles.

Leaving the Wound uncovered. It is well known that wounds of the face commonly heal up, in their whole length, by first intention. This is due, in great measure, to the vital qualities 